Case Reports
in Dermatology
Case Rep Dermatol 2021;13:244-247

DOI: $10.1159 / 000509178$

Published online: April 21, 2021
(C) 2021 The Author(s)

Published by S. Karger AG, Basel www.karger.com/cde

This article is licensed under the Creative Commons Attribution-NonCommercial 4.0 International License (CC BY-NC) (http://www.karger.com/Services/OpenAccessLicense). Usage and distribution for commercial purposes requires written permission.

\title{
Bulky Condyloma Acuminata following Ustekinumab Treatment for Plaque Psoriasis: A Case Report
}

\author{
Martina Burlando Mattia Fabio Molle Emanuele Cozzani \\ Aurora Parodi
}

Section of Dermatology, DISSAL, San Martino-IST Polyclinic Hospital, University of Genoa, Genoa, Italy

\author{
Keywords \\ Condyloma acuminata $\cdot$ Plaque psoriasis · Ustekinumab · Genital warts
}

\begin{abstract}
Ustekinumab is a fully human monoclonal antibody targeting the pro-inflammatory cytokines interleukin (IL)-12 and IL-23 approved for the treatment of psoriasis and psoriatic arthritis. We report a case of a patient treated for chronic plaque psoriasis with ustekinumab who developed bulky condyloma acuminata shortly after initiating the treatment. Although ustekinumab has already been described in literature associated with other forms of human papilloma virus skin infections, this is the first case to our knowledge in which ustekinumab is associated with genital warts.

\section{Introduction}

Ustekinumab is a human interleukin (IL) 12/23 antagonist with US Food and Drug Administration and European Medicines Agency (EMA) indications to treat moderate to severe plaque psoriasis, psoriatic arthritis, and inflammatory bowel disease such as ulcerative colitis and Crohn's disease [1]. Because of the blockade of the IL-12/IL-13 pathway, which mediates antitumor and antiviral responses, ustekinumab has immunosuppressive characteristics and

\begin{tabular}{ll}
\hline & Martina Burlando \\
& Section of Dermatology, DISSAL \\
& San Martino-IST Polyclinic Hospital, University of Genoa \\
Via Pastore 1, IT-16132 Genoa (Italy) \\
martinaburlando@hotmail.com
\end{tabular}




\section{Case Reports in Dermatology}

Case Rep Dermatol 2021;13:244-247

DOI: $10.1159 / 000509178$

(c) 2021 The Author(s). Published by S. Karger AG, Basel www.karger.com/cde

Burlando et al.: Bulky Condyloma Acuminata following Ustekinumab Treatment for Plaque Psoriasis: A Case Report

can lead to an increased risk of infection, reactivation of latent infections, and malignancy in patients [2]. We present a case of a patient with psoriasis treated with ustekinumab who developed bulky genital warts shortly after initiating treatment.

\section{Case Presentation}

A 31-year-old Caucasian male presented to our dermatology clinic with a chief complaint of a progressive severe psoriasis involving the whole body surface (PASI 35). The first plaques of psoriasis appeared 5 years ago and were treated with cyclosporine at the dosage of 2.5 $\mathrm{mg} / \mathrm{kg} /$ daily, with initial clearance of his lesions. After 2 years of self-administered cyclosporine, he decided to discontinue the therapy, thus leading to a severe psoriasis rebound.

Blood examinations and X-ray were ordered, and as the patient had no contraindication, the treatment with ustekinumab was started at the initial dose of $90 \mathrm{mg}$ administered subcutaneously, followed by a 90-mg dose 4 weeks later, and then every 12 weeks thereafter. The drug was chosen for its favorable posology as well as for the availability of two different dosages, which is an advantage in overweight subjects as our patient (BMI >28). Unfortunately, his psoriasis did not improve, and the patient developed de novo bulky condyloma acuminata in the genital area approximately 3 months later. Despite 2 years of therapy with cyclosporine, a drug with known immunosuppressive abilities, the patient had never developed condylomas before the initiation of ustekinumab treatment.

On presentation, his physical examination was notable for several 10 - to 20 -mm pink and skin-colored verrucous papules on the genitalia (Fig. 1). Skin biopsy confirmed clinical suspicion of condylomata acuminata. Ablative therapy such as cryosurgery or other similar modalities was not recommended because of the size of the warts and concerns over the Koebner phenomenon. There was also concern about using imiquimod therapy because of its stimulation of interferon- $\alpha$ production, which may exacerbate psoriasis. The patient had not been vaccinated for human papilloma virus (HPV).

After 7 months of treatment, we decided to discontinue ustekinumab due to the lack of clinical response of his psoriasis and decided on a surgical laser approach, which led to the complete clinical regression of condylomas. However, as he was no longer receiving biologic therapy, the number of psoriatic lesions started to increase. We decided to change class of the biologic, and brodalumab was started. After only 1 month on brodalumab, psoriasis improved very quickly, but the condyloma reappeared.

\section{Discussion}

The immunosuppressive characteristics of ustekinumab arise from the blockade of the IL-12/IL-23 pathway, which is necessary for host's defense against various viral, bacterial, and fungal pathogens [2].

Anderson et al. [3] in fact hypothesize that ustekinumab blocks the IL-12/IL-23 pathway by decreasing the Th1 response, leading to lower levels of IFN- $\gamma$ and IL-2, and weakening the patient's ability to fight off HPV infection.

Currently, no other case to our knowledge has been described in the literature regarding the development of genital condylomas during ustekinumab treatment.

\section{Karger'=}




\section{Case Reports in Dermatology}

\begin{tabular}{l|l}
\hline Case Rep Dermatol 2021;13:244-247 \\
\hline DOI: 10.1159/000509178 & $\begin{array}{l}\text { c 2021 The Author(s). Published by S. Karger AG, Basel } \\
\text { www.karger.com/cde }\end{array}$ \\
\hline
\end{tabular}

Burlando et al.: Bulky Condyloma Acuminata following Ustekinumab Treatment for Plaque Psoriasis: A Case Report

A search on PubMed revealed that there are few reports of condyloma appearing during biologic therapy and most refer to anti TNF $\alpha$; however, none of them involve the anti-IL$12 /$ IL-23 axis and the new anti-IL-17 class [4]. Although all these therapies have immunosuppressive properties, the risk of HPV infection remains relatively low.

The Medical Board of the National Psoriasis Foundation suggests that prior to starting biological therapy, all patients should be asked about their vaccinating profile [5, 6]. HPV vaccination is recommended for unvaccinated females up to the age of 26 years and for males up to the age of 21 years. This could reduce the incidence of wart recurrence and may possibly make them easily treatable.

\section{Statement of Ethics}

All procedures adopted in the present study were in respect to the ethical standards in the World Medical Association Declaration of Helsinki. The subject gave his written informed consent to publish the present case (including publication of the image).

\section{Conflict of Interest Statement}

The authors have no conflicts of interest to declare.

\section{Funding Sources}

The authors did not receive any funding.

\section{Author Contributions}

Study conception and design: M.B., M.F.M., E.C., A.P. Acquisition of data: M.B., M.F.M. Drafting of the manuscript: M.B., M.F.M. Critical revision: E.C., A.P.

\section{References}

1 Langley RG, Lebwohl M, Krueger GG, Szapary PO, Wasfi Y, Chan D, et al.; PHOENIX 2 Investigators. Long-term efficacy and safety of ustekinumab, with and without dosing adjustment, in patients with moderate-tosevere psoriasis: results from the PHOENIX 2 study through 5 years of follow-up. Br J Dermatol. 2015;172(5):1371-83.

2 Winthrop KL, Mariette X, Silva JT, Benamu E, Calabrese LH, Dumusc A, et al. ESCMID Study Group for Infections in Compromised Hosts (ESGICH) Consensus Document on the safety of targeted and biological therapies: an infectious diseases perspective (Soluble immune effector molecules [II]: agents targeting interleukins, immunoglobulins and complement factors). Clin Microbiol Infect. 2018 Jun;24 Suppl 2:S21-40.

3 Anderson ME, Queen D, Vance SL, Geskin LJ. Ustekinumab-associated disseminated verrucae. JAAD Case Rep. 2018 Nov;4(10):1030-3.

4 Kim SY, Solomon DH. Tumor necrosis factor blockade and the risk of viral infection. Nat Rev Rheumatol. 2010 Mar;6(3):165-74. 


\section{Case Reports in Dermatology}

\begin{tabular}{l|l}
\hline Case Rep Dermatol 2021;13:244-247 \\
\hline DOI: 10.1159/000509178 & $\begin{array}{l}\text { C } 2021 \text { The Author(s). Published by S. Karger AG, Basel } \\
\text { www.karger.com/cde }\end{array}$ \\
\hline
\end{tabular}

Burlando et al.: Bulky Condyloma Acuminata following Ustekinumab Treatment for Plaque Psoriasis: A Case Report

5 Nordgaard-Lassen I, Dahlerup JF, Belard E, Gerstoft J, Kjeldsen J, Kragballe K, et al.; Danish Society for Gastroenterology. Guidelines for screening, prophylaxis and critical information prior to initiating anti-TNFalpha treatment. Dan Med J. 2012 Jul;59(7):C4480.

6 Wine-Lee L, Keller SC, Wilck MB, Gluckman SJ, Van Voorhees AS. From the Medical Board of the National Psoriasis Foundation: vaccination in adult patients on systemic therapy for psoriasis. J Am Acad Dermatol. 2013 Dec;69(6):1003-13.

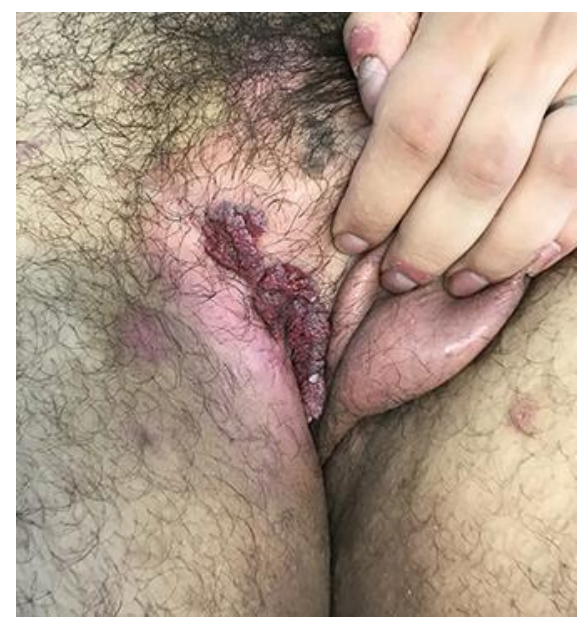

Fig. 1. Bulky condyloma acuminata in the genital area. 